\title{
Social policy and the production of age norms for later life: The case of ageing policies in Chile
}

\author{
By RoDRIGo GONZÁLEZ VELASTÍN*
}

\begin{abstract}
Social policies have been recognised as guiding narratives that promote and legitimise certain models of ageing. This finding, however, has been achieved by studies focussed on the reality of developed countries. Furthermore, little is known about how social policies promote age norms for later life in the context of developing countries. This research addresses this knowledge gap and focusses on the Chilean case, paying particular attention to what age norms are promoted by the two national ageing policies implemented by this country in 1996 and 2012. A critical discourse analysis method was used to identify the ways in which each policy conceptualises ageing as a social problem and the prescriptive behaviours and expectations that each policy promotes regarding old age. Results indicate that a rhetorical evolution can be observed in the analysed period, as each policy promotes different later life depictions and social norms.
\end{abstract}

Keywords: ageing, age norms, Chile social policy. 
International Journal of Ageing and Later Life

\section{Introduction}

Since 1950, an increased life expectancy in Chile has produced a rapidly ageing demographic within Chilean society (Gobierno de Chile 2012). Late life $^{1}$ has become the longest phase of the life course in Chile and is also the phase in which most of the Chilean population is living (Huenchuan et al. 2007). The accelerated ageing process took place over a period of 50 years, which is very short compared to the period of time in which these transformations took place in developed countries (Meza 2003). Considering these data, ageing is currently a relevant topic in the Chilean public debate; however, most of the discussion has been undertaken around the pressure it creates on the pensions system. Chile is recognised as a liberal welfare regime, and the social care and social security policies are strongly constructed over a principle of individual responsibility. This means the quality of life of the Chilean population and, specifically, of the older adults, mainly depends on their socioeconomic background. As a consequence of this, the discussion about ageing has been strongly framed from a reductionist perspective that reduces population ageing to its economic consequences.

This means cultural changes and social expectations affecting the older adults' life that come with population ageing remain unexplored for the Chilean context. Despite this, the Chilean government has designed and implemented two ageing policies over a period of 16 years (1996-2012), which have an important role in defining what ageing well means in Chile. From a public policy perspective, these policies represent normative social discourses about ageing and are interesting resources to be analysed.

Social discourses regarding later life contribute to the production of age norms, that is "expectations regarding age-appropriate behaviours (...) that dictate what roles, timing of life events and social interactions are expected from individuals according to their age" (Chung \& Jung 2013: 1336). In the case of old age, age norms fulfil the role of legitimising particular ways in which individuals should age, promoting certain social roles, activities and social environments through which older adults are expected to construct a mature identity and remain integrated into society.

${ }^{1}$ From the age of 60 years onwards a person is considered an older adult in Chile. 
Older adults, however, have historically experienced the challenge of ageing in line with shifting social expectations. The public discourse about ageing has experienced a significant change of direction in recent decades (Chapman 2005; Moulaert \& Biggs 2013). This discourse has evolved from one that called for excluding older adults from productive activities and encouraging them to retire, to one in which older adults are asked to remain active and autonomous, and contribute to society for as long as possible (Fealy et al. 2012).

The active role of international organisations in producing this shift in public discourses regarding old age reflects that social policy is a fertile ground for the production of age norms. Most of the research in the field, however, has been focussed on the internalisation of certain age norms by older adults rather than on their production and promotion by public discourses.

There is plenty of research focussed on what behaviours, activities, dispositions and social roles are perceived by older adults as contributing to "successful ageing" (Chung \& Yung 2013; Fernández-Ballesteros et al. 2010; Sousa et al. 2004; Tate et al. 2003). In contrast, only a few studies have explored the role of social policies in producing age norms for later life (Biggs 2001; Biggs \& Powell 2001; Moulaert \& Biggs 2013; Powell 2005; Raymond \& Grenier 2013). Nevertheless, all of these studies have the remarkable limitation that they are mostly focussed on the reality of developed countries.

Considering this gap, this paper focusses on the age norms promoted by social policies in Chile between 1996 and 2012. This paper understands social policies as normative narratives that define what social expectations older Chilean adults have to cope with regarding the behaviours they are expected to show, the social roles they are expected to fulfil and the spaces in which they are expected to be.

\section{Literature review}

\section{Age norms}

Age norms have been conventionally defined as age-related social expectations regarding the behaviour of individuals (Chung \& Yung 2013; Neugarten et al. 1965; Settersen 2003). These norms shape expectations 
International Journal of Ageing and Later Life

about the roles, activities and transitions that individuals should perform across their lives (Chung \& Yung 2013). Settersen (2003) operationalises the concept and suggests that age norms are (a) prescriptive and proscriptive rules; (b) based on social consensus; (c) and enforced by social sanctions. These sanctions can not only assume formal expressions in the form of political, legal or economic regulations but can also appear through informal ways such as ostracism, ridicule or gossip. Thereby, age norms encourage and restrict certain behaviours, and in cases where individuals choose courses of action that do not fit with these expectations, they may lose important formal or informal supports and be sanctioned by society.

The idea of age norms has been widely used in the life course approach, which understands life as a sequence of age-related transitions and status passages (Heinz, Huinink \& Weymann 2009; Mortimer \& Shanahan 2003). As individuals become aware of these transitions and the challenges that come with them, they start to develop certain agerelated expectations about how and when people should move through these passages. In that way, age norms contribute to the construction and reinforcement of a normative life course (Chung \& Yung 2013; Elder 1975; Settersen 2003).

Considering that this research is focussed on old age, age norms will be understood as normative expectations that define what the appropriate behaviours for older adults are. It must be recognised that the aforementioned components of age norms, such as the social consensus underpinning them or the attached social sanctions through which they are reinforced, exceed the scope of this article. Considering this, the study will be mainly focussed on identifying the prescriptions for or proscriptions against certain behaviours, which are embedded in Chilean ageing policies.

\section{Empirical research: age norms in later life}

Assuming that age norms are internalised and put into practice by individuals (Settersen 2003), exploring expectations that individuals have regarding certain phases of the life course can give us a more precise understanding of which age norms are constraining each phase of life. In this sense, identifying those factors that older adults declare as contributing 
to "good ageing" reflects the current social expectations about later life. There is plenty of research in this field, and it is characterised by a lack of consensus regarding what concept should be used to refer to a normatively constructed "good ageing process" (Nosraty et al. 2015). Concepts such as "positive ageing," "successful ageing," "healthy ageing," "ageing well," among others, are normally found in these studies (FernándezBallesteros et al. 2010; Nosraty et al. 2015).

Despite the confusion that the use of diverse terms might produce, all of these studies aim to identify those factors that older adults associate with a "good ageing process." Although some studies suggest that the perception of age norms can vary among different age groups (Chung \& Jung 2013), some evidence suggest that there is minimum variability in the expectations about late life across cultures and age groups (Fernández-Ballesteros et al. 2010; Nosraty et al. 2015). Among revised studies, four main factors are normally stressed as contributors to "good ageing." These factors are "good health," "independence," "social interaction" and "subjective well-being."

In terms of health, "absence of chronic disease" (Hsu 2007; Phelan et al. 2004; Rozanova et al. 2014); "healthy habits" (Rozanova et al. 2014; Tate et al. 2003); "adequate cognitive and physical capacity" (Nosraty et al. 2015; Von Faber et al. 2001); and "adopting healthy life styles" (Sousa et al. 2004) were mentioned as the key components to the pursuit of "good ageing." Regarding independence, "being independent" (Hsu 2007); "being able to take care of myself" (Fernández-Ballesteros et al. 2010; Phelan et al. 2004) and "financial independence and decision-making" (Nosraty et al. 2015; Tam 2013) were recognised as important factors. Social interaction was mainly composed of "adequate family relationships" (Fernández-Ballesteros et al. 2010; Hilton et al. 2012; Tate et al. 2003) and "social roles and activity" (Bowling 2007; Sousa et al. 2004). Finally, subjective well-being is mainly composed of indicators such as "accepting change" (Knight \& Ricciardelli 2003; Ryff 1989; Von Faber et al. 2001) and "having goals, interest and projects" (Fernández-Ballesteros et al. 2010; Tate et al. 2003).

\section{The production of age norms for later life in the academic discourse}

Some authors stressed that gerontological theory has been a fertile ground for the production of age norms. Chapman (2005) uses the concept of 
"ageing well" to address how different gerontological theories produced prescriptions for how individuals should age and others, such as Fernández-Ballesteros et al. (2010) and Nosraty et al. (2015), state that those factors that older adults identify as contributing to "good ageing" tend to coincide with those suggested by gerontological theories. Therefore, it is possible to state that gerontological academic discourse creates a "professional gaze," which helps to "shape legitimate forms that ageing might take" (Estes et al. 2003: 64).

For seminal gerontological approaches such as the activity (Cavan et al. 1949; Havighurst \& Albrecht 1953) and disengagement theories (Cumming \& Henry 1961), adult ageing brings with it the challenge of finding a new role after retirement. This argument is reinforced by a narrative claiming that ageing comes with a process of physical, cognitive and social decay. For the disengagement theory, older adults become less equipped to fulfil productive roles as a consequence of this decay, whilst for activity theory they experience an increasing sense of maladjustment to society as they are required to retire from productive roles.

From this negative diagnosis, these theories state that a re-adaptation between individual and society is required in later life. The disengagement theory suggests a mutual withdrawal between older adults and society, and consequently the former are expected to find a new role in the private sphere, restricting their social interaction to close family and friends. From a different stance, activity theory states that older adults should maintain high levels of activity, conserving and adapting non-productive activities from midlife in their old age. It can be observed that both theories clearly define expected courses of action for older adults, and also particular social spaces in which a new identity should be adopted during later life.

A second group of approaches is composed by the continuity theory (Atchley 1989, 1999; Costa et al. 1980) and the selective optimisation with compensation model (SOC) (Baltes \& Baltes 1993), among others. These approaches focus on the subjective challenges that ageing raises for older adults. In opposition to the seminal theories, these approaches conceptualise ageing as a phase of the life course that entails gains and losses. In this scenario, individuals are encouraged to optimise these gains and losses, keeping a positive self-concept during old age. For the continuity theory, this can be reached if older adults are able to develop a subjective 
Social policy and the production of age norms for later life

perception in which changes experienced during old age are coherent with significant past experiences, preferences, social relations and environments. Older adults are expected to retain certain activities and social relations that were significant for them in the past. These activities work as a means to construct a perceived inner structure which brings sense to the present.

In the SOC model, older adults are expected to put personal strategies into practice to maximise the gains and minimise the losses that come with ageing. This model states that these strategies should articulate three processes. The first process is selection, which entails prioritisation of particular activities and relations above others. The second process is optimisation; here older adults invest time and energy to maximise the benefits that come from selected objects or social relations. The third process is compensation, through which individuals adjust their capacities to their context to obtain the maximum benefits of particular activities and relationships. As older adults are successful in articulating these processes, they harmonise their personal resources with the context.

Finally, a third group of approaches, such as successful ageing, active ageing and productive ageing (Butler et al. 1990; Estes et al. 2003; Morrow-Howell et al. 2001; World Health Organization 2002), assume a pragmatic perspective in which ageing, from a structural perspective, is conceptualised as a waste of human resources. In these views, ageing challenges individuals to remain "useful for society." This implies that older adults are expected to be autonomous and active, and also that work or work-related activities are promoted as ideal spaces to construct an identity and to maintain them integrated in society.

\section{Social policies and the production of age norms in later life}

Considering that this research aims to understand how social policies in Chile construct age norms for later life, it is important to understand how this has been studied in different contexts. Surprisingly, only five key studies specifically focussed on this area were found (Biggs 2001; Biggs \& Powell 2001; Moulaert \& Biggs 2013; Powell 2005; Raymond \& Grenier 2013). The first group are those studies conducted by Biggs and Powell (2001) and Biggs (2001), which have two aspects in common. Both are focussed on social policies implemented in the United Kingdom, and point 
International Journal of Ageing and Later Life

out that changes in policy models are accompanied by changes in narratives about adult ageing.

Biggs and Powell (2001) assume an historical perspective to analyse how two different narratives regarding adult ageing were displayed in the United Kingdom during the post-war period and during the marketisation of social services. According to these authors, during the post-war period, welfare policies depicted older adults as inactive and dependent. In this narrative, the dependence of public care in areas such as health and pensions provided a relatively firm ground to build a mature identity. In contrast, during the marketisation of social services, older adults were conceptualised as active consumers, being encouraged to make choices among different life styles and social service providers. This transition reflects how dependency first, and individual responsibility later, were defined as the expected behaviour for older adults in two different sociopolitical contexts.

From a similar perspective, Biggs (2001) uses a narrative approach to analyse the "positive ageing" policies implemented in the United Kingdom during the late 1990s. His findings concluded that "positive ageing" policies entailed a turn of direction in the United Kingdom from perceiving older adults as consumers and dependents, to recognising them as active participants in society. In doing so, certain expected behaviours in later life were promoted, depicting older adults as "autonomous older people, actively involved in their communities, achieving joy through the return of work and voluntary activities" (Biggs 2001: 13). The author suggests, however, that the idea of "civic participation" promoted by this narrative was reduced to a claim for work and near-work situations as the only legitimate space to construct an identity in old age.

In contrast with the aforementioned studies, Moulaert and Biggs (2013) focussed on the international policy level, aiming to trace the origin of the concept of "active ageing." The authors suggest that "active ageing" policies were promoted internationally between 1994 and 2006, to produce normative prescriptions about what it is to "age-well." In line with Biggs (2001), Moulaert and Biggs (2013) suggest that, under the promise that multiple contributions to society could be made during later life, active ageing policies tend to encourage a longer working life. The authors go further to suggest that active ageing policies act as a "conduct of conduct" (Foucault 1994), making individuals aware that they are responsible for 
dealing with the negative and positive consequences that come with a longer life such as poverty, unemployment or illness. Therefore, active ageing policies have produced a new narrative of later life, in which autonomy, self-determination, empowerment and productive contribution are raised as expected behaviours.

Finally, studies conducted by Powell (2005) and Raymond and Grenier (2013) analyse how different models for ageing are promoted in certain policy domains. Powell (2005) focussed on family and ageing policies implemented in the United Kingdom during the late 1990s, when the idea of "grandparenting" was strongly promoted. Through these initiatives, older adults were encouraged to become mentors and offer their experience to their family or to other families by acting as grandparents. The author suggests that these policies create a rhetoric in which older adults are encouraged to be active citizens and construct an ageing identity based on the role of social contributors.

In a similar approach, Raymond and Grenier (2013) analysed three policies of senior participation implemented in Canada between 2005 and 2011, paying special attention to the extent that these policies promote norms and expectations of older adult participation. In their findings, the authors state that these policies have given a new meaning to participation, re-interpreting it as social contribution and individual responsibility. They point out that this new definition has consequences for older adults, as they are now expected to be actively involved in local decision-making.

All of these studies reflect that social policies have the capacity to promote certain social discourses, which constrain the life of older adults and define social expectations regarding their behaviour and the spaces in which they are expected to construct and perform an identity. It also can be noted that these studies suggest that social policies have created a narrative in which activity, autonomy and contribution in later life are increasingly promoted.

\section{Methods and design}

\section{Research question}

This research aims to answer the question: Which age norms have been promoted by the Chilean ageing policies between 1996 and 2012? By considering 
International Journal of Ageing and Later Life

that age norms are social expectations regarding later life, it is possible to assume that they are produced as social discourses in the domain of language. In line with this idea, social policies were considered as narratives, and a qualitative approach was selected as the most suitable answer to the research question.

\section{Sample}

By following a theoretical sample strategy (Creswell 2012), two key documents were selected as the study sample. The first document is the "National Policy for Older Adults" (Gobierno de Chile 1996) which is referenced in this study as "Policy A." This was the first ageing policy implemented in Chile and was the result of a technical commission established during a left-wing government led by the political coalition called "Concertación." The second selected document is the "National Policy for Positive Ageing 2012-2025" (Gobierno de Chile 2012) which is referenced in this study as "Policy B." It was designed during the rightwing government in 2012, and it is the current national ageing policy in Chile. These policies were the only ageing policies that have been implemented by 2016.

\section{Data analysis strategy}

These policies were analysed through a critical discourse analysis. This technique is characterised by providing an analytical tool that takes ideologies, social relations and political context into account (Fairclough 1995; Van Dijk 2011). With this technique, language is considered a social practice and we focus on how power is enacted and reproduced by the text (Van Dijk 2011). This means that attention is put not only on what these policies state but also on the underlying assumptions underpinning these statements.

\section{Coding}

Taking into consideration those aspects stressed in the literature review, the coding process aimed to cover two main dimensions of analysis. The first is the way in which each policy conceptualises ageing as a 
Table 1. List of codes

\begin{tabular}{|c|c|}
\hline Ageing as a social problem & Age norms \\
\hline $\begin{array}{ll}- & \text { Poverty } \\
\text { - } & \text { Increased dependency } \\
\text { - } & \text { Positive aspects of ageing } \\
\text { - } & \text { Ageing as a social challenge } \\
\text { - } & \text { Intergenerational solidarity } \\
\text { - } & \text { Debt with the past } \\
\text { - } & \text { Respect and dignity } \\
- & \text { Prevention } \\
- & \text { Cultural change is required } \\
- & \text { Social adjustment is required } \\
- & \text { Idealisation of older adults } \\
- & \text { Making ageing visible } \\
- & \text { Abuse } \\
- & \text { Social exclusion }\end{array}$ & $\begin{array}{ll}- & \text { Autonomy } \\
\text { - } & \text { Individual responsibility } \\
\text { - } & \text { Association } \\
\text { - } & \text { Activity } \\
\text { - } & \text { Contribution to society } \\
\text { - } & \text { Social interaction } \\
\text { - } & \text { Civic participation } \\
- & \text { Family } \\
- & \text { Subjective well-being } \\
- & \text { Knowledge } \\
- & \text { Good health } \\
- & \text { Social integration } \\
- & \text { Functional capacity } \\
- & \text { Economic security } \\
- & \text { Leisure activities } \\
- & \text { Self-care }\end{array}$ \\
\hline
\end{tabular}

social problem. The second focusses on which age norms are promoted by each policy. Therefore, both policies were codified twice in order to identify how, through the language used, they construct particular understandings of ageing as a problematic phase of life, and how they legitimise certain modes in which individuals should manage the ageing process. A total of 81 pages were analysed and 30 codes emerged from this analysis (see Table 1), and the information contained by them was analysed in a second stage to identify the dominant discourses underlying each policy. The data were analysed using the software NVivo version 10 .

\section{Results}

It has to be considered that the analysed policies were delivered in different moments of the Chilean history. Policy A was delivered in 1996 during the government of Eduardo Frei Ruiz-Tagle (1994-2000), which was the 
International Journal of Ageing and Later Life

second democratic government after the era of dictatorship (between 1973 and 1990). Despite President Frei being a leader of the left-wing coalition called "Concertación," he was a militant of the Christian Democratic Party, which represents a conservative view close to the Catholic Church. On the other hand, Policy B delivered in 2012 was designed under the right-wing government of Sebastian Piñera (2010-2014) and accordingly was produced under a liberal ideology that considers individual responsibility as a foundational principle of the Chilean welfare regime. These different viewpoints entail different assumptions that can be noted in the narratives constructed in both policies.

\section{How do Chilean ageing policies conceptualise ageing as a social problem? \\ Policy A (1996): The need for a cultural change}

There is a dominant rhetoric in Policy A, which states that population ageing is not a problem in itself, but the problem is how Chilean society perceives later life. As can be observed in the following excerpt, the social imaginary regarding later life is dominated by negative attributes such as decline and passivity. From this recognition, a narrative addressing the necessity of changing this perception is constructed throughout the whole document.

"[Chilean society perceives later life] as a phase of inactivity, illness, decrepitude and, in general, passivity." (p. 5)

Policy A constructs two main discourses to support the idea that a cultural change regarding the way later life is perceived is required. The first introduces the idea of "intergenerational debt," by arguing that the political, social, economic and cultural situation in Chile in 1996 was a product of the work of older generations. Thereby, ideas such as intergenerational solidarity and retribution are raised by this discourse. Chilean society should recognise the contribution that past generations have made to the country.

"What Chilean society is currently, in regard to social, economic, political and cultural development is the heritage that older adults have given to the next generations. The younger generations have a debt with older adults." (p. 2) 
The second discourse aims to contest the idea of older adults being social and economic burdens, and depicts them as a type of living heritage that should be appreciated by the Chilean society. This is a discourse that overemphasises certain positive attributes conventionally associated with old age, suggesting that they are intrinsic features of the mature subject. Thereby, this discourse tends to promote an excessive idealisation of older adults, depicting them as transcendent subjects.

"Chilean society should learn to perceive and value the moral heritage, experience and spiritual and cultural richness that older adults carry." (p. 5)

Altogether, the discourse of intergenerational debt and that of idealisation support the necessity for changing the social perception of older adults within Chilean society. This need is addressed in the general objective of this policy, which is stated as follows:

"[it is necessary] to achieve a cultural change in the population's perception of older adults and the treatment given to them, which entails a different perception of the ageing process itself, and also implies providing better levels of quality of life for older adults." (p. 5)

As it can be noted, the underlying assumption of this general objective is that a positive perception of older adults by the Chilean society will have a direct impact on their quality of life. This rationale produces an oversimplification of the problem of ageing, reducing it to issues such as discrimination and stigmatisation. By this rationale the problem is not the ageing population, but ageism. In addition, it can be noted that this rationale depicts older adults as passive subjects, by suggesting that society should integrate older adults, rather than older adults themselves assuming an active position to remain engaged in society. Older adults become secondary observers in solving the social and cultural challenges that ageing brings to the Chilean society. This is contradictory as passivity was initially identified in this policy as a factor constituting the negative perception of old age that, in theory, this policy declares to contest.

Policy A suggests that to "make ageing visible" is the first step to encourage a positive perception of older adults. During the late 1990s, there was no public institution exclusively focussed on ageing and aged care in Chile. The policy points out the necessity of creating an institution centred on ageing affairs focussed on two major tasks. First, to create 
International Journal of Ageing and Later Life

social awareness about the importance of population ageing. Second, to promote a positive image of older adults.

"It is a requirement to create a public department to coordinate, guide and monitor public policies focused on ageing (...) This department should also encourage awareness among social organizations about the importance of ageing (...) It will be impossible to change the negative social perception of older adults without the support of a public department leading this task." (p. 8)

The narrative goes beyond the problem of the lack of public institutions to deal with an aged population and produces a rhetoric that stresses the fact that population ageing is not exclusively a challenge to the Chilean State. As can be observed in the next excerpt, this policy produces a rhetoric aimed at engaging the Chilean society as a whole with the issue of adult ageing. Later life is not depicted as an individual problem nor as a political problem, but as an issue concerning community.

"It is necessary to stress that the problems experienced by older adults cannot be solved only by the action of the State. Instead, to a large extent, the problems that come with ageing should be solved by the community itself". (p. 5)

Overall, this policy is actually weak in proposing concrete measures to deal with an aged population. Only a few measures are proposed in this document, such as increased services and human resources to respond to the needs of an aged population and creating a public department focussed on these issues. This means that, rather than being an actual plan of action, this policy pretends to be a guiding narrative that states certain values and principles as those which have to lead a change of perception regarding older adults in the 1990s.

\section{Policy B (2012): Ageing as phase of decline and vulnerability}

Policy A idealises older adults, conceiving them as "living heritage" and disregards the concrete problems they experience in later life. In contrast, Policy B recognises that ageing is a phase of the life course that entails gains and losses. Starting from this recognition, this policy addresses the practical challenges that emerge in later life, and states that ageing becomes a social problem because the Chilean society should be able to provide a good quality of life to an increasing number of older adults. 
"Being an older adult is an ambivalent experience, which is characterised by positive factors such as expectations of remaining active and leaving behind duties and responsibilities, but also by negative aspects such as health problems and the fear of becoming dependent on others."(p. 8).

Policy B mainly focusses on identifying the negative aspects of later life to then propose certain ways to cope with these aspects. In fact, no positive aspects of ageing are mentioned across the document. It produces a narrative that conceptualises older adults as vulnerable subjects, by using a medical discourse which depicts later life as stage characterised by the prevalence of health problems.

"older adults in Chile are experiencing health problems such as hypertension and diabetes (...) Three in ten older adults suffer arterial hypertension, one in ten suffers diabetes and almost all of them are sedentary." (p. 16).

This idea is then used by this policy to address the need to implement strategies to increase protective factors among older Chilean adults. This discourse goes further and states what would be the most undesirable condition for older adults; that is, losing their autonomy and becoming dependent of others. Therefore, risk factors and health problems are stressed as central components of later life in this narrative. Ageing is matched with physiological decline, and the older adult is depicted as a frail body.

"The combination of chronic illness with risk factors (...) will bring an increased risk that older adults experience decline in their functional health, requiring support of others to fulfil basic tasks such as walking, sitting or going to bed." (p. 16)

There is a second discourse contributing to the conceptualisation of older adults as vulnerable subjects, but this is based on social issues. This discourse is drawn upon the idea of social exclusion, and stresses that as the individual ages, he/she becomes more likely to be excluded by society in multiple domains. This is reflected by the following excerpts, in which social exclusion assumes different expressions such as abuse, economic exclusion and isolation.

"The social integration of older adults is inadequate (...) There are studies suggesting that one out of three older adults are experiencing some type of abuse." (p. 20) 
International Journal of Ageing and Later Life

"There are currently five economically active people for each older adult, but in 2025 there will be only three economically active contributors for each older adult. Consequently, older adults will have less economic support from other people, and also they will have to deal with a longer period of retirement due to the increase in life expectancy." (p. 21)

"Later life is a phase of life in which people experience changes in their identity (...) This raises the risk of becoming isolated." (p. 46)

Similar excerpts can be observed across the document, reflecting that vulnerability in later life is also conceptualised as being composed of social factors. Therefore, the older adult is not only depicted as a vulnerable body in this policy but also as an individual facing the risk of losing his/her rights, dignity and his/her role as a social actor.

Which age norms for later life have been promoted by Chilean ageing policies?

\section{Policy A (1996): finding new spaces of social recognition}

The age norms promoted by this policy are consistent with the way in which ageing is conceptualised as a social problem, that is, a cultural problem involving a negative perception of older adults that leads to their social exclusion. As this policy focusses on the cultural adaptation required for an ageing society, it produces a narrative in which age groups that are not older adults are targeted.

"The whole population, through the family, the educational system and social media, should receive adequate education regarding their own ageing process, and also information about adequate ways to establish social relations with older adults." (p. 7)

According to this policy, later life is essentially the moment when older adults are expected to find new spaces of positive social recognition in non-productive roles. In this sense, it legitimises certain social spaces as the most suitable ones in which to find this recognition and construct a mature identity. Family is promoted as the "natural" place to undertake this task. In this narrative, family is expected to provide older adults with the positive recognition which they do not receive in the public sphere, and it is accordingly conceived as the main channel of social integration in later life. 
"Family is the social space in which the human being finds affection, positive recognition and love. There, one satisfies his/her basic needs required for his/her development (...) Family assumes a greater importance for older adults. The normal situation is one in which older adults find in their adult children, brothers and sisters and grandchildren, a strong material, spiritual and emotional support." (p.7)

Family is also depicted as the most suitable space to encourage the principle of intergenerational solidarity, which is a foundation of this policy. The policy assumes that kinship relationships provide a fertile ground to encourage this solidarity. This view is drawn upon a normative assumption that considers family as the elemental unity of society, which has a main role in producing social change.

"It is convenient to point out that solidarity is based on mutual love and recognition, thereby, the natural space where this solidarity is produced is family. Here, this solidarity is materialized through relationships between parents, children and grandparents." (p. 3)

"If intergenerational solidarity is strengthened within family, then it will be possible to promote a better treatment of the aged in the public domain." (p.3)

Participation in older adult organisations is recommended as other suitable spaces for older adults; however, it is recognised as a second-level objective in this policy. This aims to foster the agency of older adults, by recognising them as autonomous and able to contribute to society. It is possible, however, to identify an internal contradiction regarding the social expectations that this policy constructs regarding later life. On the one hand, older adults are encouraged to find recognition in their private life, particularly in their family, but on the other hand they are encouraged to assume a protagonist's role in the public sphere.

"Participating in older adult organizations, older adults find spaces for their self-development and satisfaction (...) By participating in these organizations they become legitimate interlocutors to inform local and national authorities of their problems and also to offer their contribution to the community (...) Participation transforms older adults into protagonists and allow them to fulfil public roles which are recognized by Chilean society. Thus, participation allows older adults to remain integrated in society." (p. 8) 
International Journal of Ageing and Later Life

In addition, this policy encourages the use of time in "meaningful ways" during later life. Here, "meaningful" means to focus on activities that contribute to maintaining a good health condition. This policy promotes the idea that late life is a phase of "preservation" rather than one in which individuals pursue new goals. In doing so, the future is not considered a meaningful dimension in older adults' lives, and the present becomes the most important principle in organising life during old age. Older adults are neither expected to assume active roles in domains such as politics or work, nor are they expected to be active contributors within their families, for instance, through supporting childcare tasks. This idea is supported by a depiction of later life as phase of contemplation and leisure:

"It is necessary to encourage the use of free-time in activities that contribute to personal development, and physical and psychological health of older adults." (p. 7).

"This period [later life] is of special importance, recreation activities such as tourism, artistic expression and physical care (...) Those activities are important for maintaining good health and they are also a right of everyone." (p. 7)

\section{Policy B (2012): vulnerable subjects require surveillance}

Policy B conceptualises later life as a phase dominated by risks and vulnerability, and therefore it aims to promote a model of ageing that prescribes certain courses of actions to deal with these issues. This policy produces a discourse in which autonomy, understood as the capacity of "solving by oneself the obstacles that the interaction with the environment raises" (p.16), is constructed as the legitimate way to cope with challenges that ageing brings.

"Good ageing is strongly associated with autonomy, that is, the capacity for older adults to extend, optimise and use favourable health conditions (...) to achieve a good quality of life during later life." (p. 8)

By this rationale, "ageing well" is reduced to having an adequate physical capacity to interact with the social environment, and avoiding the undesirable condition of becoming dependent on others. It can be observed, however, that this policy promotes a limited conceptualisation of autonomy, which reduces it to a physiological condition, ignoring 
social and political dimensions of autonomy such as decision-making capacity and self-determination.

Once physiological autonomy is established as the normative goal in later life, this policy advocates for certain mechanisms to achieve this goal. Overall, it was found that these mechanisms are organised around a general principle. This principle states that later life is a phase of the life course requiring surveillance, that is, a phase of life that should be monitored to prevent older adults from losing their physical autonomy. Departing from this general principle, the policy produces two narratives. The first encourages older adults to undertake self-surveillance over their bodies. The second states that an external observer is required to monitor the older adult's physiological condition.

The narrative of self-surveillance promotes an ethic of self-care, in which older adults are expected to assume an active role in maintaining their physical autonomy for as long as possible by cultivating certain behaviours. This discourse aims to create awareness of the importance of healthy habits to keep physical autonomy and aims to place them as organising principles of behaviour in later life.

"Self-care entails healthy habits such as a nutritious diet, good personal hygiene, adequate resting and cognitive stimulation." (p. 20)

At a second level, the narrative of surveillance legitimises the process of the State monitoring the aged body. This can be observed in the prevalence of a great diversity of medical controls designed to monitor older adults' health status and prevent a decline in their autonomy. Multiple mechanisms are mentioned throughout the document to undertake this surveillance. Some of them focus on detecting physical decline, whilst others aim to monitor cognitive problems such as depression or dementia. These mechanisms aim to minimise the risks of becoming dependent and, when it is required, to define strategies of intervention in order to increase or maintain the older adult's autonomy.

"It is proposed that a Model of Integral Care for Older Adults is implemented, which aims to identify risk factors associated with dependency and loss of cognitive capacity." (p. 18);

"The National Plan of Dementia aims to identify (...) the extent of damage of the cognitive faculties, in order to ascertain if it is low, moderate or high and then define what measures are required to intervene in this situation." (p. 38) 
International Journal of Ageing and Later Life

Despite the evident importance attributed to the State in undertaking surveillance over older adults' bodies, it has to be stressed that the narrative of individual responsibility becomes dominant across this policy.

“(...) Active participation of older adults is required [to achieve positive ageing] (...) They have to assume the role of active subjects in the construction of their own destiny." (p. 3)

This discourse is reinforced by the fact that family, community and the State are expected to fulfil a secondary role in providing support during later life. Community, family and the State assume an active role in supporting older adults only after they have made the transition from being autonomous to being dependent. Furthermore, this policy makes older adults responsible for delaying the transition from autonomy to irreversible dependency for as long as possible.

"Autonomous older adults can live independently or with their family, but as they lose their autonomy, their family are to be encouraged to assume an active role in providing them adequate care." (p. 18)

"[When a high mental damage is identified] it is necessary to strengthen familiar and communitarian mechanisms of support" (p. 18); "[When the level of physical dependence increases] placing older adults in rehabilitation program in day care centres, or providing care to them in public care institutions (ELEAM) needs to be considered." (p. 18)

Finally, Policy B also creates new expectations regarding later life as it encourages older adults to assume roles that have been ignored by Policy A. This is observed in a new interest for depicting longer working lives as a solution to reduce the economic vulnerability associated with later life. This new interest for encouraging older adults to remain economically active reinforces the preference for an individual management of social risks during old age, and is functional to a narrative that justifies a weak role of the Chilean State in providing welfare to older adults.

"It is necessary to promote the participation of older adults in the labour market. To do so, it is necessary to make economic incentives to encourage companies to employ older adults; to prohibit age discrimination and forced retirement; and implement public campaigns to promote the individual capacities of older adults and replace negative stereotypes constructed about them." (p. 48) 
Social policy and the production of age norms for later life

\section{Discussion}

This study found that Chilean ageing policies have promoted shifting age norms between 1996 and 2012. In line with Chapman (2005), it was found that different ways of defining ageing as a social problem led to completely different prescriptions regarding the ways in which individuals should age. In Policy A (1996), the underlying question is: What is required to change the way in which older adults are perceived by the Chilean society? In response to this question, a narrative calling for a positive perception and recognition of older adults was constructed. Family was positioned as the legitimate space to achieve this recognition, and accordingly older adults were encouraged to find refuge, as well as to construct and perform a mature identity in this space. Family is in that way legitimised as the natural place to be positioned later in life. This idea was in line with the seminal gerontological theories, which depicted older adults as passive and unproductive subjects, and claimed for restricted social interaction during later life (Cavan et al. 1949; Cumming \& Henry 1961; Havighurst \& Albrecht 1953).

The underlying question in Policy B (2012) is: what is required to make older adults less vulnerable subjects? A dominant narrative aimed to regulate the older adult's conduct was found as a response to this question. This policy produces a discourse that fosters self-surveillance and legitimises public surveillance over the aged subject. It is argued in this policy that surveillance is required to prevent older adults' physical and social decline, and to keep them autonomous and active for as long as possible. Therefore, this policy promotes the ethic of self-care and the public monitoring of the health status as critical factors contributing to "ageing well." These findings are in line with research conducted by Moulaert and Biggs (2013), Katz (2000), Laliberte Rudman (2006) and Raymond and Grenier (2013) among others, who stressed a current tendency to promote the stereotype of the "active and healthy subject" as the ideal older adult. In addition, these findings reflect that approaches such as active (World Health Organization 2002) and productive ageing (Morrow-Howell et al. 2001) have had a significant influence on the way Chilean ageing policies have evolved.

The observed evolution between Policy A (1996) and Policy B (2012) indicates that the Chilean policy discourse transited from a narrative 
International Journal of Ageing and Later Life

focussed on the macro-social level (Policy A) to one focussed on the micro-social level (Policy B). In the first, family and community have an important role in encouraging a positive perception and providing care to older adults, whilst in the second, older adults themselves are encouraged to assume the responsibility of dealing with the positive and negative changes that come with ageing. This transit to an increase in individual responsibility in later life has been observed by previous research (Biggs \& Powell 2001; Moulaert \& Biggs 2013) and is in line with the structural tendency to the individualisation of life trajectories and responsibilisation of risks, which have been addressed as dominant processes affecting Western societies (Beck 2002). It is necessary, however, to think about the consequences that these processes may have on individuals in a society such as Chile.

The responsibilisation of risks in later life transforms ageing into a problem of self-care, which can become an excessively complex duty for individuals if they do not have enough material and social resources to deal with this responsibility. This task can be particularly challenging in the Chilean context, where high levels of social and economic inequality (Davis-Hamel 2012); the commodification of social services such as health care and pensions (Riesco 2009); and the low levels of citizens' association observed among the Chilean population (United Nations Development Program 2004, 2010) shape a scenario in which a great number of Chileans become extremely vulnerable to social risks. This reality is no different for older adults, because they are one of the most vulnerable groups in Chile (Thumala et al. 2010).

A large number of older Chilean adults receive minimum pensions (Fundación SOL 2015) and are affiliated to the public health care system (Servicio Nacional del Adulto Mayor 2009: 91), which only provides health care for a restricted number of pathologies (Dannreuther \& Gideon 2008). Considering this scenario, it should be said that the current Chilean policy in later life reproduces the dominant discourse promoted by international organisations. That is, one that encourages individuals to be autonomous and assumes the responsibility of acquiring material and social resources to "age-well." This rationale, however, has been unreflexively promoted, disregarding the economic, cultural and social aspects that define the Chilean context and the way in which these aspects constrain the older adults' lives. 
The study also found that the promotion of individual responsibility and autonomy in later life works as a mechanism to construct internal boundaries within old age. Through this mechanism, the idea that there is a significant social transition that happens in later life is stated. This is the transition from being physically autonomous to being physically dependent. Policy B (2012) contributes to create a social imaginary in which old age is no more associated with decline, impairment and social disengagement. Those characteristics are now specifically associated with later phases of old age, to be precise, with those "close to death" stages of life. This finding is in line with the proposals of Gilleard and Higgs (2010), who state that a residual phase of later life characterised by irreversible decline and decrepitude defined as "fourth age" is increasingly prevalent in the social imaginary of ageing. Consequently, the stage of life in which older adults show a good performance in physical, mental and social domains is now labelled as "third age."

The split of later life between "third age" and "fourth age" has important consequences. On the one hand, "fourth age" now embraces all the negative attributes normally associated with later life, and "third age" receives an intrinsically positive connotation, being associated with attributes such as healthiness, activity, social engagement, etc. This may be positive as it promotes positive stereotypes of older adults. However, it has been stressed that this discourse is also favourable to policy narratives claiming for longer working lives (Moulaert \& Biggs 2013), and also to those in favour of reducing public investment in provision of adult care and health care (Ervik \& Lindén 2013). On the other hand, the emergence of a phase of life labelled as "fourth age" makes identifying differentiators - distinct from the chronological age - to define the boundary between middle age and "third age" more difficult.

In addition, it was found that age norms promoted by Chilean policies in later life do not coincide with those aspects that older adults recognise as contributing to "ageing well." According to the gerontological literature, older adults identify "good health," "independence," "social interaction" and "subjective well-being" as the main factors contributing to "good ageing" (Fernández-Ballesteros et al. 2010; Nosraty et al. 2015). "Good health" is addressed by both analysed policies as contributing to good ageing, although this aspect is more relevant in Policy B. "Independence" was absent as a component of good ageing in Policy A (1996) and 
International Journal of Ageing and Later Life

is, to some extent, addressed in Policy B under the concept of "autonomy." The latter policy, however, promotes a limited conceptualisation of autonomy, which reduces the concept to its physiological dimension and does not consider social domains such as decision-making capacity and political participation.

"Social interaction" is promoted in Policy A, which encouraged the participation in seniors' organisations and stresses the importance of intergenerational relationships. This was, however, a secondary component in this policy. In contrast, this dimension is not contained in Policy B, which focusses on the individual level and ignores the interactional domain.

"Subjective well-being" was not mentioned in Policy A, and even though it is stated as an objective in Policy B, it is not clear how this concept is defined and what factors contribute to its achievement. In summary, Chilean ageing policies have promoted a restrictive narrative of later life, which first was reduced to the necessity of being recognised and then to a normative expectation for remaining autonomous for as long as possible. In so doing, Chilean policies overlooked most of the elements that older adults themselves identify as contributing to "good ageing."

Finally, it has to be stressed that as this study considered social policies as discourses that promote certain age norms, what is not found in these discourses is also relevant. Gott and Hinchliff (2003) state that policies foster stereotypes of older adults, as they do not make reference to certain topics. This means that making certain issues invisible contributes to the belief they are irrelevant for older adults. For instance, the words "sex" or "sexuality" are not mentioned in any of the analysed policies, although there is plenty of research suggesting that this is an important issue for older adults (Gott \& Hinchliff 2003; Hurd Clarke 2006; Katz \& Marshall 2003).

The word "death" is not mentioned in Policy A, and it is only mentioned once in Policy B, even though Nosraty et al. (2015) suggest that a "good death" has become a relevant component of "good ageing" from the perspective of older adults. This attempt of avoiding the topic of death is in line with a wider tendency that was found in both policies. This tendency depicts later life as a phase dominated by present time, in which future becomes an irrelevant dimension. The "active senior" is depicted as one focussed on present, on finding spaces of recognition and on the 
preservation of his/her autonomy. This narrative is problematic if we consider that older adults themselves state that "to have projects and goals" - that is, to have some sense of a future - is an important aspect of "ageing well" (Tate et al. 2003). These issues show that Chilean ageing policies promote certain ideas at the same time that they hide others. This should make us aware that the current discourse about later life in Chile is one of multiple possible narratives about the same issue. Nothing can ensure us that this narrative could change again in the future.

\section{Acknowledgments}

All my gratitude to Irma Mooi-Reci, Ashley Barnwell and Barbara Neves from The University of Melbourne. Their comments were very useful to develop this article.

\section{Corresponding Author}

Rodrigo González Velastín, Independent researcher. Av. Simón Bolivar 4699 402, Nuñoa, Santiago, Chile. Email: rod.gonzalez.vel@gmail.com

\section{References}

Atchley, R. C. (1989). A continuity theory of normal aging. The gerontologist 29(2): 183-190.

Atchley, R. C. (1999). Continuity and Adaptation in Aging. Creating Positive Experiences. Baltimore, MD: Johns Hopkins University.

Baltes, P. B. \& Baltes, M. M. (1993). Successful Aging: Perspectives from the Behavioral Sciences. (Vol. 4). Cambridge: Cambridge University Press.

Beck, U. (2002). Individualization: Institutionalized Individualism and Its Social and Political Consequences. (Vol. 13). London: Sage.

Biggs, S. (2001). Toward critical narrativity: Stories of aging in contemporary social policy. Journal of Aging Studies 15(4): 303-316.

Biggs, S. (2004). Age, gender, narratives, and masquerades. Journal of Aging Studies 18(1): 45-58.

Biggs, S. \& Powell, J. L. (2001). A Foucauldian analysis of old age and the power of social welfare. Journal of Aging \& Social Policy 12(2): 93-112. 
International Journal of Ageing and Later Life

Bowling, A. (2007). Aspirations for older age in the 21st century: what is successful aging?. The International Journal of Aging and Human Development 64(3): 263-297.

Butler, R. N., Oberlink, M. R. \& Schechter, M. (Eds.). (1990). The Promise of Productive Aging: From Biology to Social Policy: Symposium: Papers. New York: Springer Publishing Company.

Cavan, R. S., Burgess, E. W., Havighurst, R. J. \& Goldhamer, H. (1949). Personal Adjustment in Old Age. Chicago, IL: Science Research Associates.

Chapman, S. A. (2005). Theorizing about aging well: Constructing a narrative. Canadian Journal on Aging 24(01): 9-18.

Costa Jr, P. T. \& McCrae, R. R. \& David Arenberg (1980). Enduring dispositions in adults males. Journal of Personality and Social Psychology 38: 793-800.

Creswell, J. W. (2012). Qualitative Inquiry and Research Design: Choosing among Five Approaches. Thousand Oaks, CA: Sage.

Chung, S. \& Jung, Y. (2014). Age norms for older adults among Koreans: perceptions and influencing factors. Ageing and Society 34(08): 1335-1355.

Cumming, E. \& Henry, W. E. (1961). Growing old, the process of disengagement. New York: Basic Books.

Dannreuther, C. \& J. Gideon (2008). Entitled to Health? Social Protection in Chile's Plan AUGE. Development and Change 39(5): 845-864.

Davis-Hamel, A. (2012). Successful Neoliberalism?: State Policy, Poverty, and Income Inequality in Chile. International Social Science Review 87(3/4): 79-101.

Elder, G. (1975). Age differentiation and the lifecourse. Annual Review of Sociology 1(1): 165-190.

Estes, C., Biggs, S. \& Phillipson, C. (2003). Social Theory, Social Policy and Ageing: A Critical Introduction: Critical Perspectives. Maidenhead, Berkshire: Open University Press.

Ervik, R. \& Lindén, T. S. (2013). The making of ageing policy: Framing, conceptual ambiguities and national policy developments. Cheltenham: Edward Elgar Publishing Ltd.

Fairclough, N. (1995). Critical Discourse Analysis. London: Longman.

Fealy, G., Mcnamara, M., Treacy, M. \& Lyons, I. (2012). Constructing ageing and age identities: A case study of newspaper discourses. Ageing and Society 32(1): 85-102. 
Fernández-Ballesteros, R., Garcia, L. F., Abarca, D., Blanc, E., Efklides, A., Moraitou, D. \& Patricia, S. (2010). The concept of "ageing well" in ten Latin American and European countries. Ageing and Society 30(01): 41-56.

Foucault, M. (1994). The Subject and Power. London: Penguin.

Fundación Sol. (2015) Porcentaje de jubilados con pensiones inferiors a $\$ 150.519$. Available on http://www.fundacionsol.cl/graficos/porcentaje-dejubilados-con-pensiones-inferiores-a-150-510/ (Accessed: September 15, 2015).

Gobierno de Chile. (1996). "Política nacional para el adulto mayor" [National policy for older adults]. Santiago: Gobierno de Chile.

Gobierno de Chile. (2012). "Política nacional de envejecimiento positivo 2012-2025" [National policy of positive ageing 2012-2025]. Santiago: SENAMA.

Gott, M. \& Hinchliff, S. (2003). How important is sex in later life? The views of older people. Social Science and Medicine 56(8): 1617-1628.

Havighurst, R. J. \& Albrecht, R. (1953). Older People. London: Longmans, Green.

Heinz, W. R. Huinink, J. \& Weymann, A. (2009). The Life Course Reader. Individuals and Societies across Time. Frankfurt: Campus Verlag.

Gilleard, C. \& Higgs, P. (2010). Aging without agency: Theorizing the fourth age. Aging \& Mental Health 14(2): 121-128.

Hilton, J. M., Gonzalez, C. A., Saleh, M., Maitoza, R. \& Anngela-Cole, L. (2012). Perceptions of successful aging among older Latinos, in cross-cultural context. Journal of Cross-Cultural Gerontology 27(3): 183-199.

Hsu, H. C. (2007). Exploring elderly people's perspectives on successful ageing in Taiwan. Ageing and Society 27(01): 87-102.

Huenchuan, S., González, D., Paredes, M. \& Guzmán, J. (2007) Protección y participación en la vejez: escenarios futuros y políticas públicas para enfrentar el envejecimiento en Chile. Colección documentos de Proyectos. Santiago de Chile: CEPAL.

Hurd Clarke, L. (2006). Older women and sexuality: experiences in marital relationships across the life course. Canadian Journal on Aging 25(2): 129-140.

Katz, S. (2000). Busy bodies: Activity, aging, and the management of everyday life. Journal of Aging Studies 14(2): 135-152. 
International Journal of Ageing and Later Life

Katz, S. \& Marshall, B. (2003). New sex for old: Lifestyle, consumerism, and the ethics of aging well. Journal of Aging Studies 17(1): 3-16.

Knight, T. \& Ricciardelli, L. A. (2003). Successful aging: perceptions of adults aged between 70 and 101 years. The International Journal of Aging and Human Development 56(3): 223-245.

Laliberte Rudman, D. (2006). Shaping the active, autonomous and responsible modern retiree: An analysis of discursive technologies and their links with neo-liberal political rationality. Ageing and Society 26(02): 181-201.

Meza, S. J. (2003). Demographic-epidemiologic transition in Chile, 1960-2011. Revista Española de Salud Pública 77(5): 605-613.

Morrow-Howell, N., Hinterlong, J. \& Sherraden, M. (2001). Productive Aging: Concepts and Challenges. Baltimore: JHU Press.

Mortimer, J. T. \& Shanahan, M. J. (eds.). (2003). Handbook of the Life Course. New York: Kluwer Academic.

Moulaert, T. \& Biggs, S. (2013). International and European policy on work and retirement: Reinventing critical perspectives on active ageing and mature subjectivity. Human Relations 66(1): 23-43.

Neugarten, B. L., Moore J. W. \& Lowe J. C. (1965). Age norms, age constraints, and adult socialization. American Journal of Sociology 70: 710-717.

Nosraty, L., Jylhä, M., Raittila, T. \& Lumme-Sandt, K. (2015). Perceptions by the oldest old of successful aging, Vitality $90+$ study. Journal of Aging Studies 32: 50-58.

Phelan, E. A., Anderson, L. A., Lacroix, A. Z. \& Larson, E. B. (2004). Older adults' views of "successful aging" - How do they compare with researchers' definitions? Journal of the American Geriatrics Society 52(2): 211-216.

Powell, J. L. (2005). Aging and family policy: A sociological excursion. Journal of Sociology and Social Welfare 32: 63-74.

Raymond, É. \& Grenier, A. (2013). Participation in policy discourse: New form of exclusion for seniors with disabilities? Canadian Journal on Aging 32(02): 117-129.

Riesco, M. (2009). El modelo social chileno comienza a cambiar. Revista Internacional del Trabajo 128(3): 311-330.

Rozanova, J., Noulas, P., Southwick, S. M. \& Pietrzak, R. H. (2014). Perceptions of determinants of successful aging among older US veterans: 
Results from the national health and resilience in veterans study. The American Journal of Geriatric Psychiatry 23(7): 744-753.

Ryff, C. D. (1989). In the eye of the beholder: Views of psychological well-being among middle-aged and older adults. Psychology and Aging 4(2): 195.

Servicio Nacional del Adulto Mayor. (2009). Las Personas mayores en Chile. Situación, avances y desafíos del envejecimiento y la vejez [Older adults in Chile. Current situation and challenges for ageing and later life]. Santiago: SENAMA.

Settersen, R. A. 2003. Age structuring and the rhythm of life course. In J. T. Mortimer \& M. J. Shanahan (eds.), Handbook of the Life Course (pp. 81-98). New York: Kluwer Academic.

Sousa, L., Cerqueira, M. \& Galante, H. (2004). Age variations in the perceptions of how to age successfully: An exploratory study in the Portuguese population. Reviews in Clinical Gerontology 14(04): 327-335.

Tam, M. (2013). Perceptions of successful ageing and implications for latelife learning. Studies in Continuing Education 35(3): 281-298.

Tate, R. B., Lah, L. \& Cuddy, T. E. (2003). Definition of successful aging by elderly Canadian males: The Manitoba follow-up study. The Gerontologist 43(5): 735-744.

Thumala, D., Arnold, M. \& Urquiza, A. (2010). Opiniones, expectativas y evaluaciones sobre diferentes modalidades de inclusión/exclusión social de los adultos mayores en Chile. Santiago: Colette Capriles.

United Nations Development Program. (2004). El poder, ¿para qué y para quién? [Power: for what and for whom?] Human Development Report 2004. Santiago: UNDP.

United Nations Development Program. (2010). Género, los desafíos de la igualdad en Chile. Human Development Report 2010. Santiago: UNDP.

Van Dijk, T. A. (ed.). (2011). Discourse studies: A multidisciplinary introduction. Thousand Oaks, CA: Sage.

Von Faber, M., Bootsma-van der Wiel, A., van Exel, E., Gussekloo, J., Lagaay, A. M., van Dongen, E. \& Westendorp, R. G. (2001). Successful aging in the oldest old: who can be characterized as successfully aged? Archives of Internal Medicine 161(22): 2694-2700.

World Health Organization. (2002). Active Ageing-A Policy Framework. A contribution of the World Health Organization to the Second United Nations World Assembly on Ageing. Madrid: WHO. 